\title{
Two Novel Self-compatible $S$ Haplotypes in Peach (Prunus persica)
}

\author{
Toshio Hanada ${ }^{1 * *}$, Akiko Watari ${ }^{1}$, Takanori Kibe ${ }^{1}$, Hisayo Yamane ${ }^{1}$, Ana Wünsch², \\ Thomas M. Gradziel ${ }^{3}$, Yukio Sasabe ${ }^{4 * * *}$, Hideaki Yaegaki ${ }^{5}$, \\ Masami Yamaguchi ${ }^{2 * * * *}$ and Ryutaro Tao ${ }^{1 *}$ \\ ${ }^{1}$ Graduate School of Agriculture, Kyoto University, Kyoto 606-8502, Japan \\ ${ }^{2}$ Unidad de Fruticultura, CITA de Aragón, Apartado 727, 50080 Zaragoza, Spain \\ ${ }^{3}$ Department of Plant Science, University of California, Davis, CA 95616, USA \\ ${ }^{4}$ Research Institute for Agriculture, Okayama Prefectural Technology Center for Agriculture, Forestry and Fisheries, Akaiwa 709 - \\ 0801, Japan \\ ${ }^{5}$ NARO Institute of Fruit Tree Science, Tsukuba 305-8605, Japan
}

Peach (Prunus persica) as a species is self-compatible (SC), although most other Prunus fruit tree species are partially or fully self-incompatible. We previously identified 3 mutated $S$ haplotypes, $S^{1}, S^{2}$, and $S^{2 m}$, that confer self-compatibility on commercial peach cultivars for fruit production. In this report, we identified 2 novel SC $S$ haplotypes, $S^{3}$ and $S^{4}$, among 130 peach cultivars and strains consisting mainly of ornamental cultivars and wild strains. The $S^{3}$ haplotype was found only in ornamental cultivars, while the $S^{4}$ haplotype was found mainly in wild strains. $S$-RNases in the $S^{3}$ and $S^{4}$ haplotypes appeared to have no defects in their primary structures. $S$ haplotype-specific F-box $(S F B)$ sequences were also present in the $S$ locus downstream of the $S^{3}$-and $S^{4}$-RNases. These $S F B$ sequences were in a reverse transcriptional orientation as has been reported in most other functional Prunus $S$ haplotypes; however, both $S_{F B}{ }^{3}$ and $S F B^{4}$ appeared to be mutated. DNA sequencing of the entire downstream region of $S F B^{3}$, extending about $12 \mathrm{kbp}$ to the stop codon of $S$-RNase, revealed the presence of a premature stop codon 975 bp downstream from the $S F B^{3}$ start codon. No sequence homologous to $S F B$ downstream of the stop codon was found. There was a $4946 \mathrm{bp}$ insertion in the middle of $\mathrm{SFB}^{4}$. The original $\mathrm{SFB}^{4}$ sequence, obtained by removing the inserted sequence, encodes a typical SFB. Based on the 3 previously identified peach $S$ haplotypes, we supposed that the $S^{3}$ and $S^{4}$ haplotypes were also SC pollen part mutant (PPM) $S$ haplotypes. Here, we also discuss possible reasons for all peach $S$ haplotypes identified so far having the PPM SC $S$ haplotype.

Key Words: F-box protein, pollen part mutation, self-incompatibility, SFB, S-RNase.

\section{Introduction}

Self-incompatibility is a genetically controlled pollenpistil recognition mechanism that prevents selffertilization and promotes outcrossing (de Nettancourt, 2001). Most Prunus (family Rosaceae) fruit tree

Received; November 6, 2013. Accepted; February 18, 2014.

First Published Online in J-STAGE on March 27, 2014.

This work was supported by Grants-in-Aid (nos. 20248004 and 24248007) for Scientific Research (A) from the Japan Society for the Promotion of Science (JSPS) to RT.

* Corresponding author (E-mail: rtao@kais.kyoto-u.ac.jp).

** Apple Research Station, NARO Institute of Fruit Tree Science, Morioka 020-0123, Japan.

*** Ikasa Agricultural Extension and Leading Association, Okayama Prefectural Government, Kasaoka 714-8502, Japan.

**** Faculty of Agriculture, Tokyo University of Agriculture, Atsugi 243-0034, Japan species exhibit a homomorphic gametophytic selfincompatibility (GSI) system in which self/nonselfrecognition is controlled by a single multiallelic locus, called the $S$ locus (Tao and Iezzoni, 2010; Yamane and Tao, 2009). A self-incompatibility reaction is triggered when the same $S$-allele specificity is expressed in both the pollen and pistil. Thus, growth of a pollen tube bearing either of the $2 S$-allele specificities carried by the recipient pistil is arrested in the style. During the last 2 decades, the molecules involved in GSI recognition have been identified in several plant species. It is now known that 2 separate genes, the S-ribonuclease gene ( $S$-RNase) and $S$ haplotype-specific F-box protein gene $(S F B)$ at the $S$ locus, control male and female specificities, respectively, in Prunus (Ushjima et al., 2003; Yamane et al., 2003). The term " $S$ haplotype" is used to describe variants of the $S$ locus, whereas the term " $S$ allele" is used to 
describe the variant of a given $S$ locus gene.

Mutations in $S$-RNase that lead to dysfunction of the S-RNase enzyme are known to confer selfcompatibility commonly in rosaceous and solanaceous plants that have the S-RNase-based GSI system. In sour cherry (P. cerasus) (Yamane et al., 2001), Japanese plum (P. salicina) (Watari et al., 2007), and almond (P. dulcis) (Hanada et al., 2009), self-compatibility is conferred by a low level of $S$-RNase transcription that leads to a low level of S-RNase accumulation in the style. A frameshift or substitution mutation in S-RNase that led to the translation of a dysfunctional S-RNase was also reported to confer self-compatibility in sour cherry (Tsukamoto et al., 2008, 2010). Mutations in the pollen $S$ gene, however, resulted in different outcomes depending on the taxon or the family that showed the S-RNase-based GSI. Although mutations that disrupt the pollen $S$ determinant F-box gene in Solanaceae and Plantaginaceae are supposed not to confer self-compatibility, these mutations did result in self-compatibility in Prunus (Sonneveld et al., 2005; Tao and Iezzoni, 2010; Ushijima et al., 2004; Yamane and Tao, 2009). Taken together, these findings confirm that a mutation in either $S$-RNase or SFB confers self-compatibility in Prunus (Tao and Iezzoni, 2010; Yamane and Tao, 2009).

Peach (Prunus persica) as a species is self-compatible (SC), although most other fruit tree species in the genus Prunus are partially or fully self-incompatible. We previously investigated the $S$ locus of 40 peach cultivars and strains consisting mainly of Japanese commercial cultivars for fruit production (Tao et al., 2007). Among them, we identified $3 S$ haplotypes, $S^{l}, S^{2}$, and $S^{2 m}$, all of which appeared to encode mutated dysfunctional SFB (Tao et al., 2007). The $S^{l}$ haplotype is a pollen part mutant (PPM) version of the almond $S^{k}$ haplotype, while the $S^{2}$ haplotype is a PPM version of the Japanese plum $S^{a}$ haplotype. The $S^{2 m}$ haplotype is a mutant version of the peach $S^{2}$ haplotype, in which both $S$-RNase and $S F B$ are mutated, while only $S F B$ is mutated in the $S^{2}$ haplotype. Considering that most Japanese commercial peach cultivars for fruit production are descendants of 'Shanhai Suimitsuto (Shang Hai Shui Mi Tao)', a Chinese cultivar known as 'Chinese Cling' (Yamamoto et al., 2003), there should be unidentified novel peach SC $S$ haplotypes in cultivars and wild strains that originated from other regions.

In this study, we identified 2 novel SC $S$ haplotypes, $S^{3}$ and $S^{4}$, among 130 peach cultivars and strains consisting mainly of ornamental cultivars and wild strains. The $S$-RNases in the $S^{3}$ and $S^{4}$ haplotypes appeared to be intact, while the $S F B$ s in both $S$ haplotypes were truncated. As reported previously for the 3 identified peach $S$ haplotypes, the $S^{3}$ and $S^{4}$ haplotypes were assumed to be PPM SC $S$ haplotypes. Here, we discuss the possible reasons why all peach $S$ haplotypes identified so far are PPM SC $S$ haplotype.

\section{Materials and Methods}

\section{Plant materials}

A total of 130 peach cultivars and strains consisting mainly of ornamental cultivars and wild strains were selected from peach germplasm collections at the University of California at Davis (USA), the NARO Institute of Fruit Tree Science (Japan), the Research Institute for Agriculture Okayama Prefectural Technology Center for Agriculture, Forestry and Fisheries (Japan), and the Centro de Investigación y Tecnología Agroalimentaria (CITA) de Aragón (Spain). The origin and description of all cultivars analyzed are shown in Table 1 . In addition to the 130 cultivars and strains, 2 Japanese fresh fruit cultivars, 'Shimizuhakuto' $\left(S^{l} S^{2 m}\right)$ and 'Chiyomaru' $\left(S^{2} S^{2}\right)$, grown at the experimental farm of Kyoto University, were used as references for the $S$ haplotypes in this study. Young leaves were collected in the spring of 2005-2007, frozen in liquid nitrogen, lyophilized, and stored at $-20^{\circ} \mathrm{C}$ until used.

\section{DNA extraction}

Total DNA was isolated from lyophilized young leaves using the CTAB method or the Nucleon Phytopure plant and fugal DNA extraction kit (GE Healthcare, Piscataway, NJ, USA) as described previously (Hanada et al., 2009).

\section{PCR-based genotyping}

Total isolated DNA was used as a template for PCRs using the Pru-C2 and Pru-C4R primer set as described previously (Tao et al., 1999). This primer set was designed to detect the length polymorphism in the second intron in S-RNase. Because it appeared that PCRs using the Pru-C2/Pru-C4R primer set were unable to amplify $S^{4}$-RNase effectively, we occasionally performed $S^{4}$-RNase allele-specific PCRs using the S4-RNase F3 and S4-RNase R5 primer set to determine the presence of the $S^{4}$-RNase allele when it was present heterozygously with other $S$-RNase alleles. A primer set for the dCAPS marker, S2Dra-F and S2Dra-R, was used to distinguish between $S^{2}$-RNase and $S^{2 m}$-RNase, as described by Tao et al. (2007). The oligonucleotide primer sequences used in this study are listed in Table 2.

\section{DNA gel blot analysis}

Five micrograms of total DNA was digested using EcoRI or HindIII, run on $0.8 \%$ agarose gel, and transferred to a nylon membrane (Biodyne Plus; Pall, Port Washington, NY, USA). Hybridization was performed using a DIG-dUTP-labeled probe (Roche Diagnostics, Basel, Switzerland) obtained by PCR labeling with sweet cherry $S^{I}$-RNase cDNA and the Pru-C2/Pru-C4R primer set, and washed under low stringency conditions, as described previously (Tao et al., 1999). Hybridization signals were detected using chemiluminescent substrate CDP-Star (New England Biolabs, Ipswich, MA, USA) 
Table 1. Cultivars and strains used in this study and their $S$ haplotypes.

\begin{tabular}{|c|c|c|c|c|}
\hline No. & Cultivar or strain & $S$ haplotype ${ }^{z}$ & Planting location $^{y}$ & Origin \\
\hline 1 & Nepal Peach Col. No. 84-102 & $S^{l} S^{l}$ & NIFTS & Nepal \\
\hline 2 & Nepal Peach Col. No. 84-114 & $S^{l} S^{l}$ & NIFTS & Nepal \\
\hline 3 & Nepal Peach Col. No. 84-120 & $S^{l} S^{l}$ & NIFTS & Nepal \\
\hline 4 & Nepal Peach Col. No. 84-125 & $S^{l} S^{l}$ & NIFTS & Nepal \\
\hline 5 & Nepal Peach Col. No. 84-131 & $S^{l} S^{l}$ & NIFTS & Nepal \\
\hline 6 & Nepal Peach Col. No. 84-133 & $S^{l} S^{I}$ & NIFTS & Nepal \\
\hline 7 & Nepal Peach Col. No. 84-137 & $S^{l} S^{I}$ & NIFTS & Nepal \\
\hline 8 & Nepal Peach Col. No. 84-155 & $S^{l} S^{I}$ & NIFTS & Nepal \\
\hline 9 & Nepal Peach Col. No. 84-B-201 & $S^{l} S^{I}$ & NIFTS & Nepal \\
\hline 10 & Nepal Peach Col. No. 84-B-206 & $S^{l} S^{I}$ & NIFTS & Nepal \\
\hline 11 & Nepal Peach Col. No. 85-119-B & $S^{l} S^{l}$ & NIFTS & Nepal \\
\hline 12 & Nepal Peach Col. No. 85-125 & $S^{l} S^{l}$ & NIFTS & Nepal \\
\hline 13 & Nepal Peach Col. No. 85-379 & $S^{l} S^{l}$ & NIFTS & Nepal \\
\hline 14 & Nepal Peach Col. No. 85-4021 & $S^{I} S^{I}$ & NIFTS & Nepal \\
\hline 15 & Nepal Peach Col. No. 85-4022 & $S^{l} S^{I}$ & NIFTS & Nepal \\
\hline 16 & Nepal Peach Col. No. 85-4067 & $S^{l} S^{l}$ & NIFTS & Nepal \\
\hline 17 & Nepal Peach Col. No. 85-4083 & $S^{l} S^{l}$ & NIFTS & Nepal \\
\hline 18 & Nepal Peach Col. No. 85-4087 & $S^{l} S^{l}$ & NIFTS & Nepal \\
\hline 19 & Nepal Peach Col. No. 85-4092 & $S^{l} S^{l}$ & NIFTS & Nepal \\
\hline 20 & Nepal Peach Col. No. 86-IV-36 & $S^{l} S^{l}$ & NIFTS & Nepal \\
\hline 21 & Pakistan Prunus Col. No. 95-26 & $S^{l} S^{l}$ & NIFTS & Pakistan \\
\hline 22 & Pakistan Prunus Col. No. 95-27 & $S^{l} S^{l}$ & NIFTS & Pakistan \\
\hline 23 & $1470.9 \mathrm{~B}$ & $S^{l} S^{I}$ & UC Davis & Pakistan \\
\hline 24 & $1474.10 \mathrm{~B}$ & $S^{l} S^{I}$ & UC Davis & Pakistan \\
\hline 25 & $1475.10 \mathrm{C}$ & $S^{l} S^{l}$ & UC Davis & Pakistan \\
\hline 26 & $1477.10 \mathrm{~B}$ & $S^{l} S^{l}$ & UC Davis & Pakistan \\
\hline 27 & Churkoc & $S^{l} S^{l}$ & UC Davis & Pakistan \\
\hline 28 & Hunshu & $S^{l} S^{l}$ & UC Davis & Pakistan \\
\hline 29 & Thulu & $S^{l} S^{l}$ & UC Davis & Pakistan \\
\hline 30 & Hekito (Double colored) & $S^{l} S^{l}$ & Okayama & China (Ornamental Peach) \\
\hline 31 & Okayama Yaseitou Asahikawa-2 & $S^{l} S^{l}$ & NIFTS & Japan (Wild Peach) \\
\hline 32 & Okayama Yaseitou Kamogawa-1 & $S^{l} S^{I}$ & NIFTS & Japan (Wild Peach) \\
\hline 33 & Nagano Yaseitou-Wase & $S^{l} S^{l}$ & NIFTS & Japan (Wild Peach) \\
\hline 34 & Noto 3 & $S^{l} S^{l}$ & NIFTS & Japan (Wild Peach) \\
\hline 35 & Terute Suimitsu & $S^{l} S^{l}$ & NIFTS & Japan (Ornamental Peach) \\
\hline 36 & Nepal Peach Col. No. 84-115 & $S^{l} S^{2}$ & NIFTS & Nepal \\
\hline 37 & Nepal Peach Col. No. 84-119 & $S^{l} S^{2}$ & NIFTS & Nepal \\
\hline 38 & Chalpachu & $S^{l} S^{2}$ & UC Davis & Pakistan \\
\hline 39 & Noto 2 & $S^{l} S^{2}$ & NIFTS & Japan (Wild Peach) \\
\hline 40 & Noto 8 & $S^{l} S^{2}$ & NIFTS & Japan (Wild Peach) \\
\hline 41 & Jing Hong & $S^{l} S^{2 m}$ & NIFTS & China \\
\hline 42 & Jing Hong Tao & $S^{l} S^{2 m}$ & NIFTS & China \\
\hline 43 & Shen Zhou Bai Xue & $S^{l} S^{2 m}$ & NIFTS & China \\
\hline 44 & Hoko & $S^{l} S^{2 m}$ & Okayama & China \\
\hline 45 & Tououbo & $S^{l} S^{2 m}$ & Okayama & China \\
\hline 46 & Hekito (Beni) & $S^{l} S^{2 m}$ & Okayama & China (Ornamental Peach) \\
\hline 47 & Kimumu Nakamineyuumei & $S^{l} S^{2 m}$ & NIFTS & Japan (Wild Peach) \\
\hline 48 & Yaezaki Bantou O.P. No. 1 & $S^{l} S^{3}$ & NIFTS & Japan (Ornamental Peach) \\
\hline 49 & Okayama Yaseitou Asahikawa-1 & $S^{l} S^{4}$ & NIFTS & Japan (Wild Peach) \\
\hline 50 & Nepal Peach Col. No. 84-121 & $S^{l} S^{4}$ & NIFTS & Nepal \\
\hline 51 & Okayama Yaseitou Kamogawa-2 & $S^{l} S^{4}$ & NIFTS & Japan (Wild Peach) \\
\hline 52 & Nagano Yaseitou-Bansei & $S^{l} S^{4}$ & NIFTS & Japan (Wild Peach) \\
\hline 53 & Akahayazaki & $S^{2} S^{2}$ & NIFTS & Japan (Ornamental Peach) \\
\hline 54 & Akashidare & $S^{2} S^{2}$ & NIFTS & Japan (Ornamental Peach) \\
\hline 55 & Amami Yaseitou-1 & $S^{2} S^{2}$ & NIFTS & Japan (Wild Peach) \\
\hline 56 & Amami Yaseitou-2 & $S^{2} S^{2}$ & NIFTS & Japan (Wild Peach) \\
\hline 57 & Chichibu 1 & $S^{2} S^{2}$ & NIFTS & Japan (Wild Peach) \\
\hline 58 & Chichibu 4 & $S^{2} S^{2}$ & NIFTS & Japan (Wild Peach) \\
\hline 59 & Nepal Peach Col. No. 84-522 & $S^{2} S^{2}$ & NIFTS & Nepal \\
\hline 60 & Nepal Peach Col. No. 86-III-210 & $S^{2} S^{2}$ & NIFTS & Nepal \\
\hline 61 & Nepal Peach Col. No. 86-V-169 & $S^{2} S^{2}$ & NIFTS & Nepal \\
\hline 62 & Nepal Peach Col. No. 87-VIII-67 & $S^{2} S^{2}$ & NIFTS & Nepal \\
\hline 63 & Pakistan Prunus Col. No. 95-25 & $S^{2} S^{2}$ & NIFTS & Pakistan \\
\hline 64 & Golden Glory & $S^{2} S^{2}$ & NIFTS & United States \\
\hline 65 & Golden Prolific & $S^{2} S^{2}$ & NIFTS & United States \\
\hline 66 & Silver Prolific & $S^{2} S^{2}$ & NIFTS & United States \\
\hline 67 & Swatow & $S^{2} S^{2}$ & NIFTS & China (Ornamental Peach) \\
\hline 68 & Juseitou-Aka-Yae & $S^{2} S^{2}$ & NIFTS & Japan (Ornamental Peach) \\
\hline 69 & Juseitou-Pink-Yae & $S^{2} S^{2}$ & NIFTS & Japan (Ornamental Peach) \\
\hline
\end{tabular}


Table 1. Continued

\begin{tabular}{|c|c|c|c|c|}
\hline No. & Cultivar or strain & $S$ haplotype & Planting location $^{\mathrm{y}}$ & Origin \\
\hline 70 & Da Tao & $S^{2} S^{2}$ & NIFTS & China \\
\hline 71 & Kemomo Nagoshijou & $S^{2} S^{2}$ & NIFTS & Japan (Wild Peach) \\
\hline 72 & $\mathrm{Ku}$ Tao 1 & $S^{2} S^{2}$ & NIFTS & Taiwan \\
\hline 73 & $\mathrm{Ku}$ Tao 5 & $S^{2} S^{2}$ & NIFTS & Taiwan \\
\hline 74 & Kemomno Okinawamishou-2 & $S^{2} S^{2}$ & NIFTS & Japan (Wild Peach) \\
\hline 75 & Noto 6 & $S^{2} S^{2}$ & NIFTS & Japan (Wild Peach) \\
\hline 76 & Zao Xia Lu & $S^{2} S^{2}$ & NIFTS & China \\
\hline 77 & Khanda & $S^{2} S^{2}$ & UC Davis & Pakistan \\
\hline 78 & Loimari & $S^{2} S^{2}$ & UC Davis & Pakistan \\
\hline 79 & Shintanyou & $S^{2} S^{2}$ & Okayama & China \\
\hline 80 & Juseitou (Hitoe-Shiro) & $S^{2} S^{2}$ & Okayama & Japan (Ornamental Peach) \\
\hline 81 & Juseitou (Aka-Yae) & $S^{2} S^{2}$ & Okayama & Japan (Ornamental Peach) \\
\hline 82 & Okinawa 1 & $S^{2} S^{2}$ & NIFTS & Japan (Wild Peach) \\
\hline 83 & Yaseitou 5 & $S^{2} S^{2}$ & Okayama & Japan (Wild Peach) \\
\hline 84 & Yaseitou 6 & $S^{2} S^{2}$ & Okayama & Japan (Wild Peach) \\
\hline 85 & Yaseitou 7 & $S^{2} S^{2}$ & Okayama & Japan (Wild Peach) \\
\hline 86 & Terute Beni & $S^{2} S^{2}$ & NIFTS & Japan (Ornamental Peach) \\
\hline 87 & Terute Shiro & $S^{2} S^{2}$ & NIFTS & Japan (Ornamental Peach) \\
\hline 88 & Okayama Yaseitou Tsugawa-3 & $S^{2} S^{2}$ & NIFTS & Japan (Wild Peach) \\
\hline 89 & Zao Hua Lu & $S^{2} S^{2 m}$ & NIFTS & China \\
\hline 90 & Chun Lei & $S^{2} S^{2 m}$ & NIFTS & China \\
\hline 91 & Rikaku Suimitsu & $S^{2} S^{2 m}$ & Okayama & China \\
\hline 92 & Shang Hai Shui Mi Tao & $S^{2} S^{2 m}$ & NIFTS & China \\
\hline 93 & Fukusyu & $S^{2} S^{2 m}$ & Okayama & Taiwan \\
\hline 94 & Akabana Bantou & $S^{2} S^{3}$ & NIFTS & Japan (Ornamental Peach) \\
\hline 95 & Shidare Hekitou & $S^{2} S^{3}$ & Okayama & China (Ornamental Peach) \\
\hline 96 & Yaezaki Bantou & $S^{2} S^{3}$ & NIFTS & Japan (Ornamental Peach) \\
\hline 97 & Okayama Yaseitou Asahikawa-3 & $S^{2} S^{4}$ & NIFTS & Japan (Wild Peach) \\
\hline 98 & Fei Chang Tao & $S^{2} S^{4}$ & Okayama & China \\
\hline 99 & Okayama Yaseitou Tsugawa-4 & $S^{2} S^{4}$ & NIFTS & Japan (Wild Peach) \\
\hline 100 & Okayama Yaseitou Tsugawa-5 & $S^{2} S^{4}$ & NIFTS & Japan (Wild Peach) \\
\hline 101 & Kanhitou & $S^{2 m} S^{2 m}$ & NIFTS & Japan (Ornamental Peach) \\
\hline 102 & Shen Zhou Shui Mi Tao & $S^{2 m} S^{2 m}$ & NIFTS & China \\
\hline 103 & Keihou & $S^{2 m} S^{2 m}$ & Okayama & China \\
\hline 104 & Yaseitou 3 & $S^{2 m} S^{2 m}$ & Okayama & Japan (Wild Peach) \\
\hline 105 & Yaseitou 4 & $S^{2 m} S^{2 m}$ & Okayama & Japan (Wild Peach) \\
\hline 106 & Okayama Yaseitou Tsugawa-1 & $S^{2 m} S^{2 m}$ & NIFTS & Japan (Wild Peach) \\
\hline 107 & Okayama Yaseitou Tsugawa-2 & $S^{2 m} S^{2 m}$ & NIFTS & Japan (Wild Peach) \\
\hline 108 & Kikumomo & $S^{3} S^{3}$ & NIFTS & Japan (Ornamental Peach) \\
\hline 109 & Sagami Shidare & $S^{3} S^{3}$ & NIFTS & Japan (Ornamental Peach) \\
\hline 110 & Akita Yaseitou & $S^{4} S^{4}$ & NIFTS & Japan (Wild Peach) \\
\hline 111 & Chichibu 2 & $S^{4} S^{4}$ & NIFTS & Japan (Wild Peach) \\
\hline 112 & Okayama Yaseitou Koegatouge & $S^{4} S^{4}$ & NIFTS & Japan (Wild Peach) \\
\hline 113 & Noto 5 & $S^{4} S^{4}$ & NIFTS & Japan (Wild Peach) \\
\hline 114 & Ohatsumomo & $S^{4} S^{4}$ & NIFTS & Japan (Wild Peach) \\
\hline 115 & Hiley & $S^{4} S^{4}$ & UC Davis & Unknown \\
\hline 116 & 0664. B & $S^{4} S^{4}$ & UC Davis & Unknown \\
\hline 117 & Stanwick & $S^{4} S^{4}$ & UC Davis & Unknown \\
\hline 118 & Indian Freestone & $S^{4} S^{4}$ & UC Davis & Unknown \\
\hline 119 & $1469.5 \mathrm{~B}$ & $S^{4} S^{4}$ & UC Davis & Pakistan \\
\hline 120 & $1469.7 \mathrm{~B}$ & $S^{4} S^{4}$ & UC Davis & Pakistan \\
\hline 121 & $1472.10 \mathrm{~B}$ & $S^{4} S^{4}$ & UC Davis & Pakistan \\
\hline 122 & $1473.1 \mathrm{~B}$ & $S^{4} S^{4}$ & UC Davis & Pakistan \\
\hline 123 & $1473.10 \mathrm{~B}$ & $S^{4} S^{4}$ & UC Davis & Pakistan \\
\hline 124 & Lutkoo & $S^{4} S^{4}$ & UC Davis & Pakistan \\
\hline 125 & $1485.6 \mathrm{~B}$ & $S^{4} S^{4}$ & UC Davis & Unknown \\
\hline 126 & Dai-Shirobana & $S^{4} S^{4}$ & Okayama & Japan (Wild Peach) \\
\hline 127 & Jeronimo Balate & $S^{4} S^{4}$ & CITA & Spain \\
\hline 128 & Jeronimo 2251 & $S^{4} S^{4}$ & CITA & Spain \\
\hline 129 & Zaitani (Anita) & $S^{4} S^{4}$ & CITA & United States \\
\hline 130 & Baby Gold 9 & $S^{4} S^{4}$ & CITA & United States \\
\hline
\end{tabular}

z Both $S$-RNase and $S F B$ genotypes were determined in this study.

y NIFTS: NARO Institute of Fruit Tree Science, UC Davis: University of California, Davis, Okayama: Okayama Research Institute for Agriculture, CITA: Unidad de Fruticultura, CITA de Aragón. 
Table 2. DNA sequences of oligonucleotide primers used in this study.

\begin{tabular}{llll}
\hline \multicolumn{1}{c}{ Experiment } & \multicolumn{1}{c}{ Primer name } & \multicolumn{1}{c}{ Sequence (5'-3') } & Reference \\
\hline S-RNase-based genotyping & Pru-C2 & CTATGGCCAAGTAATTATTCAAACC & Tao et al., 1999 \\
& Pru-C4R & GGATGTGGTACGATTGAAGCG & Tao et al., 1999 \\
dCAPS analysis for $S^{2}$ and $S^{2 m}$ & S2Dra-F & ACAGAAGTTCATATCCACTAATGAA & Tao et al., 2007 \\
& S2Dra-R & CAGCTTTAGCGCATCTATATTCATTT & Tao et al., 2007 \\
$S^{4}$ - $R$ Nase-specific amplification & S4-RNase F3 & GAAAGCGAATGGAACAAGCA & This work \\
& S4-RNase R5 & AACTGAGTCTTCTTCTTCTG & This work \\
Insert detection for $S F B^{I}$ & Pp_SFB1_V1F & TCCACCACCCAAATGTTAGACG & This work \\
& Pp_SFB1_R1 & AACATAGATCTCCTATGCCC & This work \\
Insert detection for $S F B^{2}$ by dCAPS analysis & Pp_SFB2_BSrBI_F & GTTGCTCTCCAATTCGGGTTCCGC & This work \\
& Pp_SFB2_R3 & CTCCTCACAACCATAACATC & This work \\
Mutation detection for $S F B^{3}$ & Pp_SFB3_F2 & TCCTTCGGGTGATTATTG & This work \\
& Pp_SFB3_R2N & AATCCGAGCACACCTACG & This work \\
Insert detection for $S F B^{4}$ & Pp_SFB4_F5 & GTTCCAAACAGAGGCCACAC & This work \\
& Pp_SFB4_R2 & GTGATAGGCTACACCATTGA & This work \\
\hline
\end{tabular}

and LAS3000-mini (Fuji Film, Tokyo, Japan) for digital images.

\section{Cloning and characterization of the $S^{3}$ and $S^{4}$ haplotypes}

A fosmid library was constructed from the genomic DNA of 'Shidare Hekitou' $\left(S^{2} S^{3}\right)$ and 'Jeronimo Balate' $\left(S^{4} S^{4}\right)$ using the CopyControl Fosmid Library Production Kit (Epicentre, Madison, WI, USA) as described previously (Ushjima et al., 2004). The library was screened using the same DIG-dUTP-labeled sweet cherry $S^{l}$-RNase cDNA probe as that used for the DNA gel blot analysis. Isolated genomic clones that contained the $S^{3}$ and $S^{4}$ haplotypes were used as templates for the DNA sequencing reaction and PCR analysis to determine the physical distance between S-RNase and SFB as described previously (Hanada et al., 2009). Deduced amino acid sequences were aligned with other Prunus $S$-RNases and SFBs using the CLUSTALW program version 1.83 provided by GenomeNet (http://www.genome. jp/tools/clustalw/).

\section{Determination of the mutation in $S F B$}

The $S F B$ allele-specific primer sets used to detect a mutation in $S F B$ were designed to check if a certain cultivar or strain had a mutated $S F B$ (Table 2). All PCR reactions contained $1 \times$ ExTaq buffer, $0.2 \mathrm{mM}$ each of dNTPs, $0.4 \mu \mathrm{M}$ of each primer, $50 \mathrm{ng}$ template total DNA, and 0.4 U TaKaRa ExTaq polymerase (TaKaRa Bio, Shiga, Japan) in a $15-\mu \mathrm{L}$ reaction volume. PCR amplification was performed using a program with initial denaturation at $94^{\circ} \mathrm{C}$ for $1 \mathrm{~min}, 35$ cycles of $94^{\circ} \mathrm{C}$ for $1 \mathrm{~min}, 56^{\circ} \mathrm{C}$ for $30 \mathrm{sec}$, and $72^{\circ} \mathrm{C}$ for $1 \mathrm{~min}$, and a final extension at $72^{\circ} \mathrm{C}$ for $7 \mathrm{~min}$. The PCR-amplified fragments from $S F B^{l}, S F B^{3}$, and $S_{F B}{ }^{4}$ were separated directly in $1 \%$ agarose gel electrophoresis and visualized with ethidium bromide under UV light. For $S F B^{2}, 5 \mu \mathrm{L}$ of the PCR products were digested with $10 \mathrm{U}$ of $B s r \mathrm{BI}$ in a $20-\mu \mathrm{L}$ reaction volume. Digested $S F B^{2}$ fragments were separated in 3\% agarose gel electrophoresis and visualized with ethidium bromide under UV light.

\section{Results}

\section{S-RNase genotyping}

The PCRs using the Pru-C2/Pru-C4R primer set to amplify the $S$-RNases of 130 peach cultivars and strains yielded bands with sizes that were different from the expected sizes from $S^{1}$ - and $S^{2}$-RNases. As shown in Figure 1, we detected novel fragments of about $600 \mathrm{bp}$ and $1600 \mathrm{bp}$ that were different in size from the bands for the $S^{I}$-, $S^{2}$-, and $S^{2 m}$-RNases, which were amplified from several cultivars and strains including 'Shidare Hekitou' and 'Jeronimo Balate'. Because we found that the DNA sequences of the novel PCR bands encoded partial S-RNase sequences, we assigned $S^{3}$ and $S^{4}$ to the $S$-RNase alleles revealed by these bands. Because we found only homozygotes for $S^{4}$-RNase in the PCR analyses, we subjected all 130 cultivars and strains to DNA blot analysis using an S-RNase-specific probe (Fig. 2). Several strains and cultivars that had heterozygous genotypes, such as $S^{1} S^{4}$ and $S^{2} S^{4}$, were detected; however, no $S^{3} S^{4}$ genotype was found. Because $S^{4}$-RNase produced longer PCR fragments than the other peach $S$-RNase alleles, PCR amplification of the $S^{4}$-RNase allele seemed to be competitively prohibited when the $S^{4}$-RNase allele was present along with other $S$-RNase alleles. Therefore, we occasionally used an $S^{4}$-RNase-specific primer set to determine the $S$-RNase genotype of the cultivars and strains. $S$-RNase genotyping by both DNA gel blot analyses and PCRs corresponded well when the PCR was performed with both Pru-C2/Pru-C4R and the $S^{4}$-RNasespecific primer sets. Because $S^{2}-R N a s e$ and $S^{2 m}-R N a s e$ cannot be discriminated by either DNA blot analyses or PCRs with the Pru-C2/Pru-C4R primer set, we used the dCAPS marker to discriminate them. The S-RNase genotypes of all analyzed cultivars determined in this study are shown in Table 1. 
Cloning and characterization of $S$ locus genes

Genomic DNA libraries of 'Shidare Hekitou' $\left(S^{2} S^{3}\right)$ and 'Jeronimo Balate' $\left(S^{4} S^{4}\right)$ were constructed and screened using an $S$-RNase gene-specific probe. Confirmation of the presence of $S F B$ and determination of the $S$-RNase allele was performed by PCR analyses. Full-length DNA sequences for the $S^{3}$ - and $S^{4}$-RNases were obtained from the genomic clones that were isolated. Both the $S^{3}$ - and $S^{4}$-RNases seemed to encode an intact S-RNase with no apparent defects. The derived amino acid sequences contained 5 conserved domains, including 2 active sites for RNase catalytic activity, and shared sequence homology with other functional Prunus S-RNase within the range of similarities that was observed between other functional S-RNases (Fig. 3). Unlike $S^{I}-, S^{2}$, and $S^{2 m_{-}}$

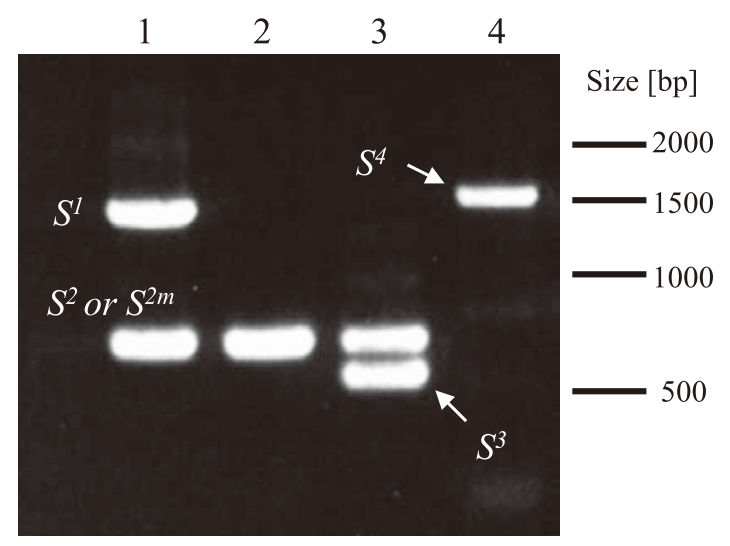

Fig. 1. PCR based S-RNase genotyping of representative peach cultivars using the Pru-C2/Pru-C4R primer set. The $S$-RNase genotypes of 'Shimizuhakuto' and 'Chiyomaru' are known to be $S^{l} S^{2 m}$ and $S^{2} S^{2}$, respectively. The unidentified bands in 'Shidare Hekitou' and 'Jeronimo Balate' were named $S^{3}$ and $S^{4}$, respectively. Lane 1, 'Shimizuhakuto' $\left(S^{l} S^{2 m}\right)$; lane 2, 'Chiyomaru' $\left(S^{2} S^{2}\right)$; lane 3, 'Shidare Hekitou' $\left(S^{2} S^{3}\right)$; and lane 4, 'Jeronimo Balate' $\left(S^{4} S^{4}\right)$
RNases, no $S$-RNase with high sequence similarity to the $S^{3}$ - or $S^{4}$-RNases was found in the International Nucleotide Sequence Databases (INSD; http://www. insdc.org/) (Tables 3 and 4). Although SFB sequences were also present in the genomic clones downstream of the $S^{3}$ - and $S^{4}$-RNases and in reverse transcriptional orientation, as reported in most other functional Prunus $S$ haplotypes, both $S F B^{3}$ and $S F B^{4}$ were mutated (Figs. 4 and 5) and appeared to encode truncated dysfunctional SFBs, as was reported previously for peach $S F B^{l}$ and $S F B^{2}$ (Fig. 5; Table 5). DNA sequencing of the entire downstream region of $S F B^{3}$ extending for about $12 \mathrm{kbp}$

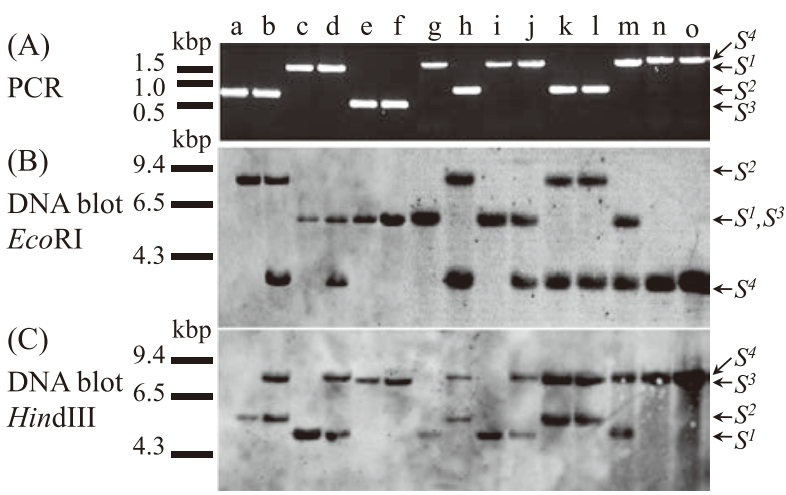

Fig. 2. S-RNase genotyping by $P C R$ and DNA gel blot analyses. (A) PCR genotyping using the S-RNase-specific Pru-C2/PruC4R primer set. (B) S-RNase genotyping by DNA blot analysis with EcoRI digestion. (C) S-RNase genotyping by DNA blot analysis with HindIII digestion. Lanes a, 'Yaseitou 4'; b, 'Fei Chang Tao'; c, 'Nagano Yaseitou-Wase'; d, 'Nagano YaseitouBansei'; e, 'Kikumomo'; f, 'Sagami Shidare'; g, 'Okayama Yaseitou Asahikawa-2'; h, 'Okayama Yaseitou Asahikawa-3'; i, 'Okayama Yaseitou Kamogawa-1'; j, 'Okayama Yaseitou Kamogawa-2'; k, 'Okayama Yaseitou Tsugawa-4'; 1, 'Okayama Yaseitou Tsugawa-5'; m, 'Okayama Yaseitou Asahikawa-1'; n, 'Dai-Shirobana'; and o, 'Okayama Yaseitou Koegatouge'.

S1-RNase
S2-RNase
S2m-RNase
S3-RNase

S3-RNase

S4-RNase

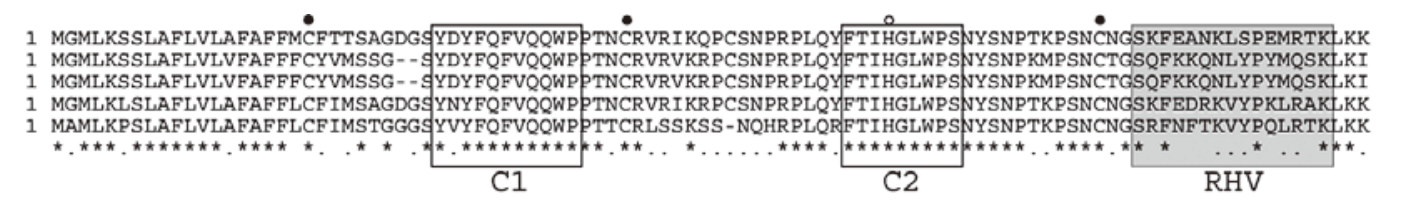

S1-RNase 100 SWPDVESGNDTWFWAEWNKHGKCं S1-RNase S2-RNase S2m-RNase S3-RNase

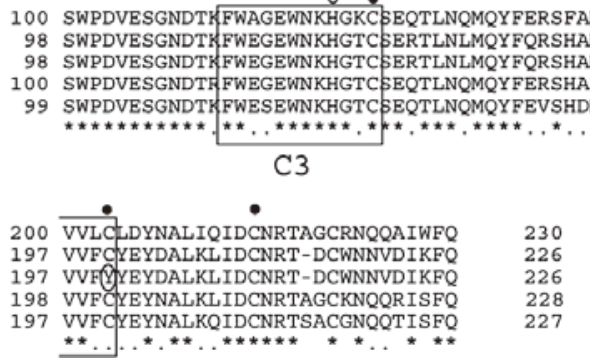

Fig. 3. Alignment of the deduced amino acid sequences of peach S-RNases. The sequences of the $\mathrm{S}^{1}-$, $\mathrm{S}^{2}-$, and $\mathrm{S}^{2 \mathrm{~m}}-\mathrm{RNases}$ were reported previously (Tao et al., 2007). Five conserved domains of rosaceous S-RNase (C1, C2, C3, RC4, and C5) are indicated in open boxes. The rosaceous hypervariable region (RHV) is indicated in a gray box. Conserved histidine residues essential for RNase catalytic activity are indicated by open circles, conserved cysteine residues are marked with closed circles, respectively above the alignment. The tyrosine residue in $S^{2 m}-R N a s e$, which is thought to be mutated from the conserved cysteine residue, is circled. The INSD accession numbers of $S^{1}-R N a s e, S^{2}-R N a s e, S^{2 m}-R N a s e$, $S^{3}$-RNase, and $S^{4}$-RNase are AB252415, AB252317, AB597186, AB537563, and AB537565, respectively. 
Table 3. Derived amino acid sequence identities (\%) of Prunus SFB (upper half) and S-RNases (lower half).

\begin{tabular}{|c|c|c|c|c|c|c|c|c|c|c|c|c|c|c|c|c|c|}
\hline & \multicolumn{2}{|c|}{ P. avium } & \multicolumn{2}{|c|}{ P. armeniaca } & \multicolumn{2}{|c|}{ P. dulcis } & \multicolumn{2}{|c|}{ P. mume } & \multicolumn{2}{|c|}{ P. salicina } & \multirow{2}{*}{$\frac{\text { P. cerasus }}{\mathrm{PcS}^{26}}$} & \multirow{2}{*}{$\frac{\text { P. speciosa }}{\text { PspS }^{1}}$} & \multicolumn{5}{|c|}{ P. persica } \\
\hline & $\mathrm{PavS}^{2}$ & PavS $^{13}$ & $\operatorname{ParS}^{1}$ & $\operatorname{ParS}^{2}$ & $\mathrm{PdS}^{\mathrm{a}}$ & $\mathrm{PdS}^{\mathrm{k}}$ & $\mathrm{PmS}^{1}$ & $\mathrm{PmS}^{7}$ & $\mathrm{PsS}^{\mathrm{a}}$ & $\mathrm{PsS}^{\mathrm{e}}$ & & & $\mathrm{PpS}^{1}$ & $\mathrm{PpS}^{2}$ & $\mathrm{PpS}^{2 \mathrm{~m}}$ & $\mathrm{PpS}^{3}$ & $\mathrm{PpS}^{4}$ \\
\hline $\mathrm{PavS}^{2}$ & - & 79.8 & 85.6 & 77.6 & 66.1 & 79.7 & 81.6 & 79.5 & 76.6 & 76.3 & 79.7 & 78.7 & 79.2 & 77.6 & - & 80.9 & 82.4 \\
\hline $\mathrm{PavS}^{13}$ & 76.4 & - & 78.5 & 77.1 & 65.2 & 78.7 & 80.2 & 76.3 & 76.3 & 78.1 & 80.3 & 79.0 & 78.4 & 77.4 & - & 84.3 & 84.4 \\
\hline $\operatorname{ParS}^{1}$ & 83.2 & 77.3 & - & 79.5 & 66.6 & 80.2 & 80.8 & 77.9 & 78.2 & 76.8 & 78.7 & 77.9 & 80.3 & 78.7 & - & 81.5 & 80.3 \\
\hline $\operatorname{ParS}^{2}$ & 74.8 & 75.1 & 75.7 & - & 67.2 & 80.8 & 81.6 & 79.7 & 76.8 & 80.2 & 77.1 & 77.1 & 80.5 & 77.3 & - & 79.6 & 76.5 \\
\hline $\mathrm{PdS}^{\mathrm{a}}$ & 50.4 & 54.2 & 54.6 & 49.1 & - & 69.1 & 68.8 & 68.7 & 66.2 & 66.1 & 68.3 & 66.8 & 68.5 & 67.3 & - & 70.4 & 67.6 \\
\hline $\mathrm{PdS}^{\mathrm{k}}$ & 81.4 & 71.1 & 75.5 & 72.6 & 51.1 & - & 80.6 & 80.6 & 80.0 & 77.3 & 80.0 & 81.1 & 99.2 & 80.5 & - & 81.5 & 79.2 \\
\hline $\mathrm{PmS}^{1}$ & 81.3 & 71.0 & 76.3 & 68.3 & 54.0 & 74.1 & - & 80.3 & 78.7 & 79.2 & 80.5 & 79.5 & 80.0 & 79.5 & - & 81.2 & 81.6 \\
\hline $\mathrm{PmS}^{7}$ & 71.2 & 74.2 & 70.4 & 67.7 & 50.0 & 67.7 & 72.8 & - & 75.8 & 77.6 & 78.9 & 77.7 & 80.3 & 77.4 & - & 81.8 & 78.2 \\
\hline $\mathrm{PsS}^{\mathrm{a}}$ & 73.9 & 69.3 & 74.8 & 69.9 & 52.7 & 71.7 & 66.5 & 64.2 & - & 74.9 & 78.4 & 84.6 & 79.5 & 97.9 & - & 77.2 & 77.1 \\
\hline $\mathrm{Ps}^{\mathrm{e}}$ & 81.9 & 73.8 & 82.5 & 76.5 & 52.9 & 76.1 & 77.7 & 73.0 & 70.8 & - & 74.4 & 76.0 & 77.1 & 75.7 & - & 77.2 & 76.3 \\
\hline $\mathrm{PcS}^{26}$ & 77.0 & 73.8 & 74.8 & 70.4 & 49.1 & 72.1 & 74.1 & 77.9 & 66.8 & 77.4 & - & 78.9 & 79.7 & 78.7 & - & 80.9 & 79.7 \\
\hline $\mathrm{PspS}^{1}$ & 78.8 & 75.1 & 77.9 & 73.0 & 50.9 & 76.1 & 69.2 & 70.4 & 77.9 & 77.0 & 73.9 & - & 80.5 & 85.6 & - & 79.0 & 79.3 \\
\hline $\mathrm{PpS}^{1}$ & 81.5 & 71.1 & 75.5 & 72.6 & 51.1 & 100.0 & 74.1 & 67.7 & 71.7 & 76.1 & 72.1 & 76.1 & - & 80.0 & - & 81.2 & 78.7 \\
\hline $\mathrm{PpS}^{2}$ & 73.9 & 68.4 & 74.3 & 69.5 & 53.1 & 71.7 & 66.5 & 63.7 & 97.8 & 70.8 & 66.8 & 78.3 & 71.7 & - & - & 78.7 & 78.2 \\
\hline $\mathrm{PpS}^{2 \mathrm{~m}}$ & 73.5 & 68.0 & 73.8 & 69.1 & 52.7 & 71.2 & 66.1 & 63.3 & 97.3 & 70.4 & 66.4 & 77.9 & 71.2 & 99.6 & - & - & - \\
\hline $\mathrm{PpS}^{3}$ & 83.2 & 77.3 & 78.9 & 74.8 & 52.9 & 81.1 & 75.0 & 72.1 & 72.6 & 80.7 & 74.8 & 83.6 & 81.1 & 72.1 & 71.7 & - & 83.3 \\
\hline $\mathrm{PpS}^{4}$ & 76.4 & 81.8 & 75.1 & 70.7 & 53.8 & 70.7 & 70.5 & 80.4 & 65.3 & 75.1 & 84.4 & 74.7 & 70.7 & 66.2 & 65.8 & 75.6 & - \\
\hline
\end{tabular}

For peach $\mathrm{SFB}^{1}, \mathrm{SFB}^{2}$ (Tao et al., 2007), and $\mathrm{SFB}^{4}$, the putative original sequences that were derived from original $S F B$ sequences reverted by removing the inserted sequence were used to calculate identities. Pav, P. avium; Par, P. armeniaca; Pd, P. dulcis; Pm, P. mume; Ps, P. salicina; Pc, P. cerasus; Psp, P. speciosa; and Pp, P. persica. The sequences used are as follows; Pav-S ${ }^{2}-\mathrm{RNase}$ (AJ298311), Pav-S ${ }^{13}-\mathrm{RNase}(\mathrm{DQ} 385842)$, Par-S ${ }^{1}$-RNase (AY587561), Par-S ${ }^{2}-R N a s e ~(A Y 587562), ~ P d-S^{a}-R N a s e ~(A B 026836), ~ P d-S^{k}-R N a s e ~(A B 252409), P m-S^{1}-R N a s e(A B 101438), P m-S^{7}-$ RNase (AB101439), Ps-S ${ }^{a}-R N a s e(A B 252411)$, Ps-Se-RNase (AB280793), Pc-S ${ }^{26}$-RNase (EU035975), Psp-S ${ }^{1}$-RNase (GU968644), Pp-S ${ }^{1}$-RNase

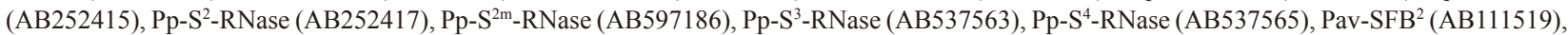
Pav-SFB $^{13}$ (DQ385844), Par-SFB ${ }^{1}$ (AY587563), Par-SFB ${ }^{2}$ (AY587562), Pd-SFB ${ }^{a}$ (AB092966), Pd-SFB (AB252408), Pm-SFB ${ }^{1}$ (AB101440),

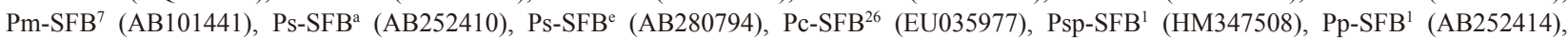

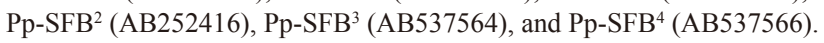

Table 4. DNA and derived amino acid length of peach S-RNases.

\begin{tabular}{|c|c|c|c|c|c|c|c|}
\hline Species & Allele & Accession $^{2}$ & Reference & $\begin{array}{l}\text { Length in } \\
\text { the genome } \\
(\mathrm{bp})^{y}\end{array}$ & $\begin{array}{l}\text { CDS } \\
(\mathrm{bp})^{\mathrm{x}}\end{array}$ & $\begin{array}{c}\text { No. } \\
\text { amino } \\
\text { acid }\end{array}$ & Note \\
\hline \multirow[t]{5}{*}{ P. persica } & $S^{l}$ & AB252415 & Tao et al., 2007 & 1884 & 693 & 230 & \\
\hline & $S^{2}$ & AB252417 & Tao et al., 2007 & 1343 & 681 & 226 & \\
\hline & $S^{2 m}$ & AB597186 & Tao et al., 2007 & 1343 & 681 & 226 & A single amino acid substitution in the $\mathrm{C} 5$ region of $\mathrm{S}^{2}$-RNase \\
\hline & $S^{3}$ & AB537563 & This work & 1197 & 687 & 228 & \\
\hline & $S^{4}$ & AB537565 & This work & 2150 & 678 & 225 & \\
\hline P. dulcis & $S^{k}$ & AB252409 & Tao et al., 2007 & 1888 & 693 & 230 & Encoding the same amino acid sequence as $P$. persica $S^{I}$-RNase \\
\hline P. salicina & $S^{a}$ & AB252411 & Tao et al., 2007 & 1277 & 681 & 226 & Encoding the same amino acid sequence as $P$. persica $S^{2}$-RNase \\
\hline
\end{tabular}

z International Nucleotide Sequence Databases (INSD; http://www.insdc.org/) accession number.

y Start codon to stop codon with introns.

${ }^{x}$ No. of nucleotide from the start codon to stop codon.

revealed the absence of a sequence homologous to $S F B$. There was a 4946 bp insertion (4244 bp insertion flanked by $351 \mathrm{bp}$ direct repeats) in the middle of $S F B^{4}$. The original $\mathrm{SFB}^{4}$ sequence can be obtained by removing the inserted sequence, and the reverted sequence encodes a typical SFB with the F-box motif at the N-terminus (Figs. 4 and 5). The predicted original $\mathrm{SFB}^{4}$ shared $70-80 \%$ amino acid identity with other SFBs. Peach $\mathrm{SFB}^{3}$ and $\mathrm{SFB}^{4}$ showed the highest amino acid sequence homology to P. avium $\mathrm{SFB}^{13}$, with $84.3 \%$ and $84.4 \%$ amino acid identity, respectively (Table 3 ). Physical dis- tances between $S$-RNase and $S F B$ in $S^{3}$ and $S^{4}$ haplotypes of peach were $12 \mathrm{~kb}$ and $4.3 \mathrm{~kb}$, respectively (Fig. 5).

\section{Mutation in $S F B$}

The PCR primer sets that were used to detect mutations in peach $S F B$ s were designed to test if the $S$ haplotypes in all the peach cultivars and strains used in this study were mutated. To detect the presence or absence of the insertion in $S F B^{I}$, we designed a primer set that amplified the $S F B^{I}$ region that contained inserted sequences. If the insertion was present, the amplified products would 
(A)

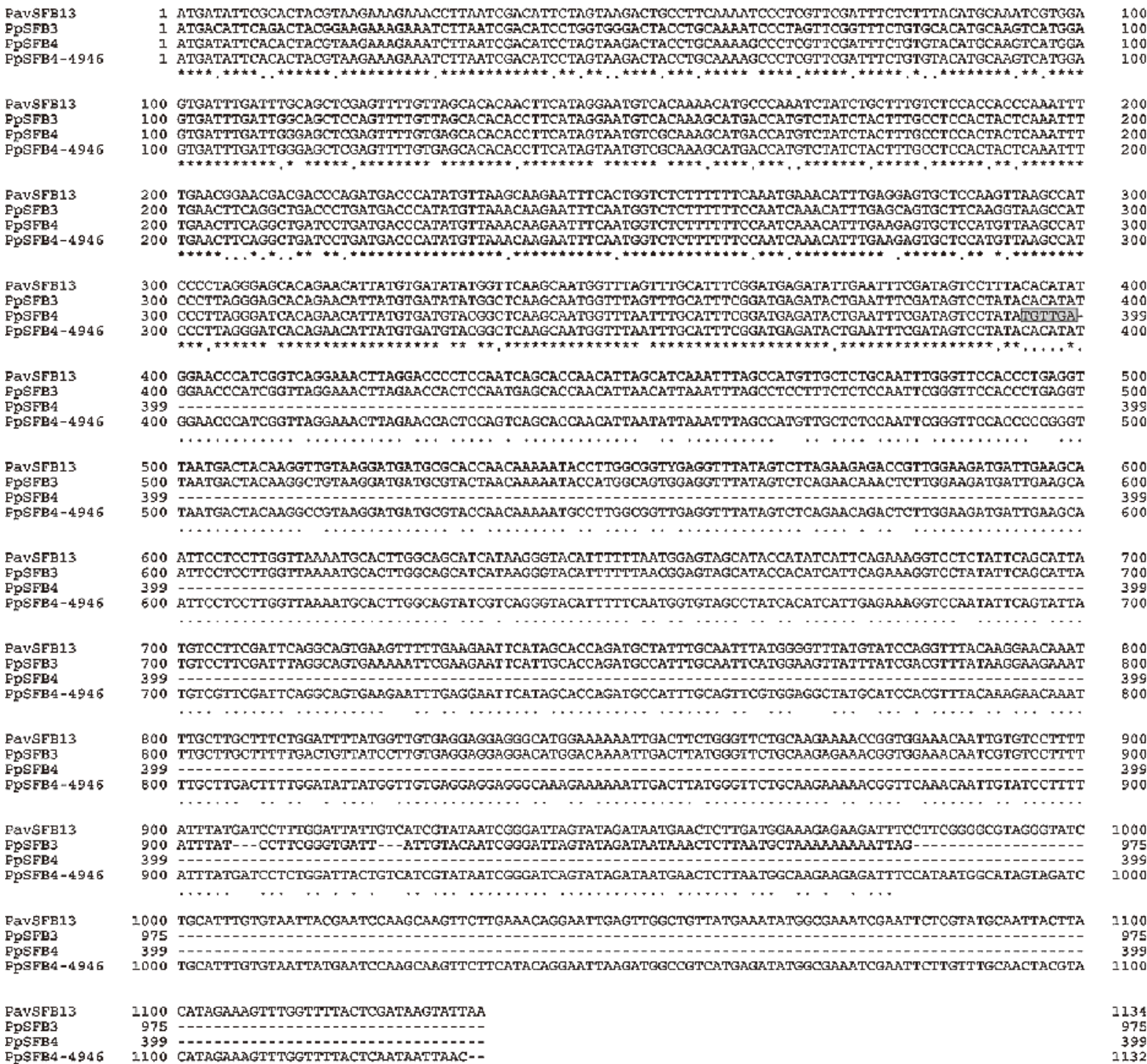

(B)

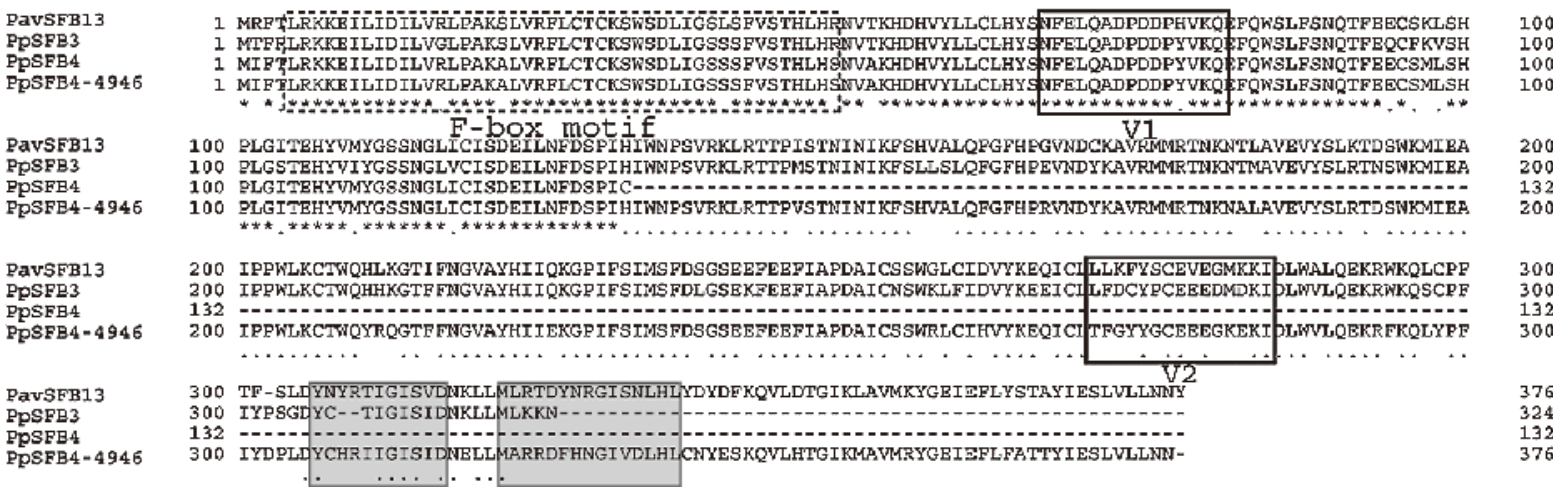

HVa

$\mathrm{HVb}$

Fig. 4. Alignments of the DNA sequences and derived amino acid sequences of peach $S F B^{3}, S F B^{4}$, and $P$. avium $S F B^{13}$. (A) DNA sequence alignment of $P$. avium SFB ${ }^{13}$ (PavSFB13), P. persica SFB 3 (PpSFB3), SFB ${ }^{4}$ (PpSFB4) with the 6 bp inserted sequence that contains a stop codon, and $S F B^{4}$ reverted by removing the inserted sequence (PpSFB4-4946). The gray box indicates the 6 bp front position of the inserted sequence in preach $S F B^{4}$. (B) Amino acid sequence alignment of deduced proteins from P. avium SFB ${ }^{13}$ (PavSFB13), P. persica SFB ${ }^{3}$ (PpSFB3), P. persica $S_{F B}^{4}$ (PpSFB4), and P. persica SFB ${ }^{4}$ reverted by removing the inserted sequence (PpSFB4-4946). The dotted box indicates the F-box motif. Two of each variable region $(\mathrm{V} 1, \mathrm{~V} 2)$ and hypervariable region $(\mathrm{HVa}$ and $\mathrm{HVb})$ are indicated by open and gray boxes, respectively. The INSD accession numbers of $P$. avium $S F B^{13}$, P. persica $S F B^{3}$, and P. persica $S F B^{4}$ are DQ385844, AB537564, and AB537566, respectively. 
be longer than the products from the original intact $S F B$. We used almond $S F B^{k}$, an original intact functional type $S F B$ of $S F B^{l}$, as a reference. As shown in Figure 6, $S F B^{l}$ from all peach cultivars and strains used in this study yielded longer products than almond $S F B^{k}$, indicating that there was no original functional $S F B^{l}$ in any of the peach cultivars and stains tested. Because the inserted sequence to $S F B^{2}$ was only 5 bp long, it was difficult to distinguish the presence of the insertion by length poly-

(A)
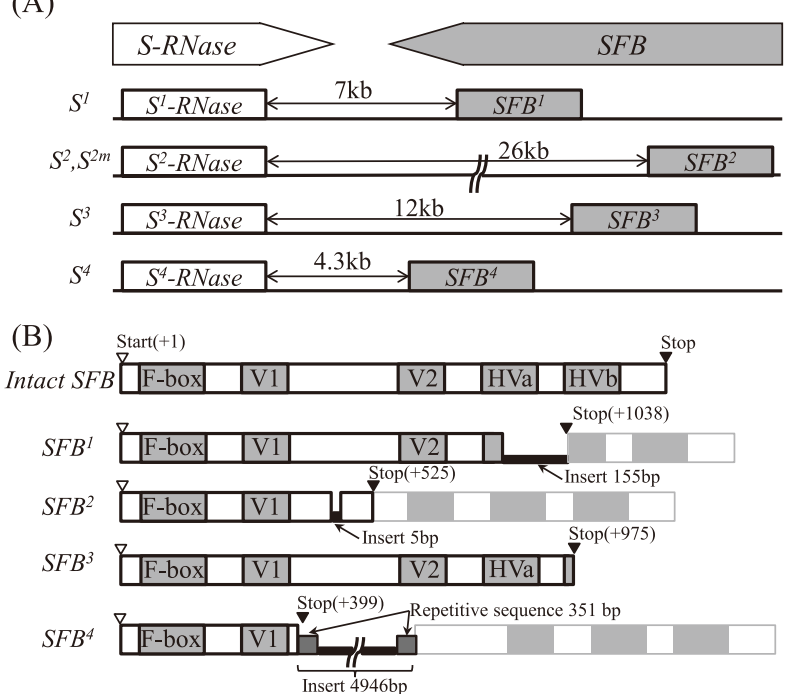

Fig. 5. Schematic diagrams illustrating the organization of $S$-RNase and $S F B$ in the peach $S$ locus region and the structure of peach $S F B$ s. (A) Schematic diagram of the organization of $S$-RNase and $S F B$ in the genomic sequence. Open and gray boxes indicate the $S$-RNase and $S F B$ coding regions, respectively. The transcriptional orientations of $S$-RNase and $S F B$ are in opposite directions relative to one another. (B) Schematic diagram of truncated peach SFBs. Gray boxes indicate the conserved structures (F-box, V1, V2, HVa, and HVb). Light gray boxes indicate the truncated region caused by the insertion and frameshift. The inserted sequence and repetitive sequence are indicated by black and dark gray boxes, respectively. morphism. We therefore developed a dCAPS marker to distinguish the original $S F B$ and the mutated $S F B^{2}$ alleles following the strategy used by Ikeda et al. (2004) to develop dCAPS markers for sweet cherry $\mathrm{SFB}^{4}$. After $B s r \mathrm{BI}$ digestion, the PCR product from mutated $S F B^{2}$ should be shorter than the product from Japanese plum $S F B^{a}$, the original functional type $S F B^{2}$ with no insertion. We found that $S F B^{2}$ in all the peach cultivars and strains used in this study were mutated $S F B$ s with 5 bp insertions. A reverse primer for the amplification of $S F B^{3}$ and a forward primer for $S F B^{4}$ were designed from the sequences that were absent in the original functional alleles. Therefore, only mutated $S F B$ alleles were amplified by PCR. All $\mathrm{SFB}^{3}$ and $\mathrm{SFB}^{4}$ in the peach cultivars and strains used in this study appeared to be mutated SFBs (Fig. 6).

\section{Discussion}

This study showed that 2 novel SC PPM $S$ haplotypes were present in peach in addition to the 3 SC PPM $S$ haplotypes, $S^{1}, S^{2}$, and $S^{2 m}$, which were identified previously. Our preliminary survey of the $S$ haplotypes of over 300 diverse peach cultivars and lines indicated that no more novel $S$ haplotypes existed (Hanada and Tao, unpublished data), although some mutated versions of the existing $S$ haplotypes may exist, as seen in the case in $S^{2 m}$ and $S^{2}$. The small number of $S$ haplotypes may indicate that peach experienced a population bottleneck and/ or positive selection on the mutated SC $S$ haplotypes. Because peach is a domesticated plant, the domestication process may have affected the population bottleneck and/or positive selection on self-compatibility. However, most of the peach-related wild species in the Prunus subgenus Amygdalus, such as $P$. mira, $P$. davidiana, and P. kasuensis, are predominantly SC (Tao, Hanada, Akagi and Gradziel, unpublished data), which makes this inference complicated. It is unclear whether the population bottleneck and/or positive selection occurred upon peach

Table 5. Length of peach $S F B$ and ther inserted sequence.

\begin{tabular}{|c|c|c|c|c|c|c|c|}
\hline Species & Allele & Accession $^{2}$ & Reference & $\begin{array}{l}\text { Inserted } \\
\text { sequence } \\
\text { (bp) }\end{array}$ & $\begin{array}{l}\text { CDS } \\
\text { (bp) }\end{array}$ & $\begin{array}{c}\text { No. } \\
\text { amino } \\
\text { acid }\end{array}$ & Note \\
\hline \multirow[t]{7}{*}{ P. persica } & $S F B^{l}$ & $\mathrm{AB} 252414$ & Tao et al., 2007 & 155 & 1098 & 365 & Mutant of $P$. dulcis $S F B^{k}$ with a 155 -bp insertion. \\
\hline & $S F B^{l}\left(\right.$ reverted $\left.^{\mathrm{x}}\right)$ & & & - & 1128 & 375 & \\
\hline & $S F B^{2}$ & AB252416 & Tao et al., 2007 & 5 & 525 & 174 & Mutant of $P$. salicina $S F B^{a}$ with a 5 -bp insertion. \\
\hline & $S F B^{2}$ (reverted) & & & - & 1131 & 376 & \\
\hline & $S F B^{3}$ & AB537564 & This work & Unknown $^{\mathrm{w}}$ & 975 & 324 & Stop codon appeared at the positon $975-\mathrm{bp}$ from the start codon \\
\hline & $S F B^{4}$ & AB537566 & This work & 4946 & 399 & 132 & A 4946-bp insertion mutation \\
\hline & $S F B^{4}$ (reverted) & & & - & 1131 & 376 & \\
\hline P. dulcis & $S F B^{k}$ & AB252408 & Tao et al., 2007 & & 1128 & 375 & \\
\hline P. salicina & $S F B^{a}$ & AB252410 & Tao et al., 2007 & & 1131 & 376 & \\
\hline
\end{tabular}

z International Nucleotide Sequence Databases (INSD; http://www.insdc.org/) accession number.

y No. of nucleotide from the start codon to stop codon.

${ }^{\mathrm{x}}$ Reverted original allele by removing the inserted sequence.

${ }^{\mathrm{w}}$ Neither the downstream sequence or the original stop codon of $S F B^{3}$ was found in the 12-kb downstream region from the stop codon of $S F B^{3}$ to the stop codon of $S^{3}$-RNase. 
(A) $S F B^{1}$
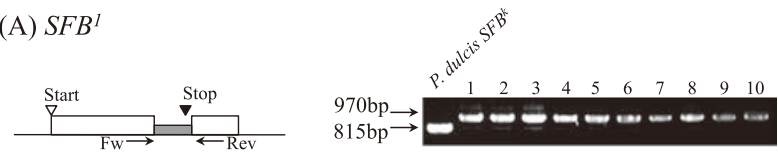

(B) $S F B^{2}$
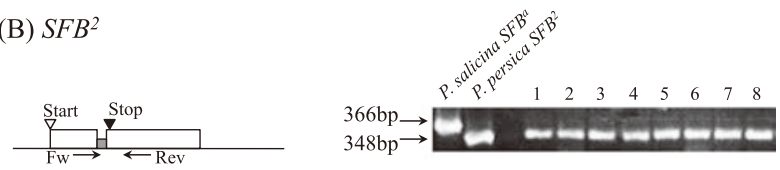

(C) $S F B^{3}$
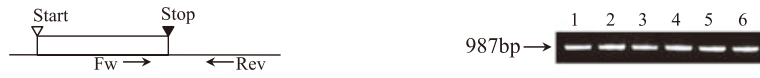

(D) $\underset{\text { Start }}{\mathrm{SFB}}$

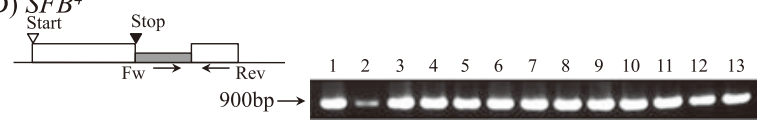

Fig. 6. Detection of mutation in the coding regions of peach $S F B$ s by PCR analysis. A specific primer pair for each $S F B$ allele was designed to detect mutation. Open boxes indicate intact coding regions. Start and stop codon positions are indicated by open and closed triangles, respectively. Arrows indicate the positions of the forward (Fw) and reverse (Rev) primers. (A) PCR amplification to detect the insertion in $S F B^{l}$. Almond $S F B^{k}$, a wild type of $S F B^{l}$, was used as a control. Lane 1, 'Jing Hong'; lane 2, 'Terute Suimitsu'; lane 3, 'Nagano Yaseitou-Wase'; lane 4, 'Nagano Yaseitou-Bansei'; lane 5, 'Noto 2'; lane 6, 'Noto 3'; lane 7, 'Noto 8'; lane 8, 'Yaezaki Bantou O.P. No. 1'; lane 9, 'Okayama Yaseitou Kamogawa-1', and lane 10, 'Okayama Yaseitou Asahikawa-1'. (B) The dCAPS marker to detect inserted sequence in $S F B^{2}$. P. salicina $S F B^{a}$, a wild type of $S F B^{2}$, was used as the control. Amplified fragment from P. persica $S F B^{2}$ was detected as different sizes after $B s r$ BI digestion. Lane 1, 'Akashidare'; lane 2, 'Akabana Bantou'; lane 3, 'Akahayazaki'; lane 4, 'Amami Yaseitou-1'; lane 5, 'Amami Yaseitou-2'; lane 6, 'Da Tao'; lane 7, 'Okinawa 1', and lane 8, 'Kimumu Nakamineyuumei'. (C) PCR amplification to detect mutation in $S F B^{3}$. Lane 1, 'Kikumomo'; lane 2, 'Sagami Shidare'; lane 3, 'Akabana Bantou'; lane 4, 'Yaezaki Bantou O.P. No. 1'; lane 5, 'Yaezaki Bantou', and lane 6, 'Shidare Hekitou'. (D) PCR amplification to detect insertion in $\mathrm{SFB}^{4}$. Lane 1, 'Okayama Yaseitou Asahikawa-1'; lane 2, 'Okayama Yaseitou Asahikawa-3'; lane 3, 'Okayama Yaseitou Tsugawa-4'; lane 4, 'Okayama Yaseitou Tsugawa-5'; lane 5, 'Okayama Yaseitou Kamogawa-2'; lane 6, 'Chichibu 2'; lane 7, 'Noto 5'; lane 8, 'Okayama Yaseitou Koegatouge'; lane 9, 'Fei Chang Tao'; lane 10, 'Ohatsumomo'; lane 11, 'Akita Yaseitou'; lane 12, 'Nagano Yaseitou-Bansei'; and lane 13, 'Dai-Shirobana'.

speciation from its progenitor species or before peach speciation. Population genetic approaches and investigation of the $S$ locus and $S$ haplotype in peach-related Amygdalus species could give important clues to address the question.

In Prunus, dysfunction of either the pistil $S$ determinant $S$-RNase or the pollen $S$ determinant $S F B$ confers self-compatibility. Thus, if evolutionary constraints or selection could be disregarded, the rate of mutation needed to confer self-compatibility would be equal for both the pistil and pollen parts in Prunus. Although the coding sequence of $S F B$ is 1.5 times longer than that for S-RNase, the $S$-RNase sequence from the initiation codon to the termination codon is longer than the
$S F B$ sequence because of the presence of introns in the $S$-RNase sequence. Considering that the causal factor of self-compatibility in peach is a mutation in pollen $S$ for all the $S$ haplotypes found, the mutation in pollen $S$ may have been preferentially selected. As we proposed previously (Tao et al., 2007), the mutation in pollen $S$ may have been selected preferentially compared with the pistil part mutants under selection pressure for SC because the pollen genotype determines the self-incompatible phenotype of pollen in the GSI system. Namely, a mutation in $S F B$ that occurs in a single pollen grain could confer self-compatibility to the original pollen grain in which the mutation first occurs. Then the SC phenotype would be transmitted to the second generation, in which the pollen grain would participate in fertilization either after self- or cross-pollination, while a mutation in $S$-RNase in a single pollen grain would be unable to confer self-compatibility to the pollen and would be only transmittable to the progeny after cross-pollination because mutations in $S$-RNase would have no effect on the SC/SI phenotype of the pollen grain. We therefore suppose that the mutation in pollen $S$ would be preferentially selected under selection pressure for SC in the GSI system. If our hypothesis is correct, peach has experienced positive selection for SC in its evolutionary path.

On the practical side, this study could give us important indications of how we can breed SC cultivars in Prunus fruit tree species, in which one of the major breeding goals is SC. Current SC breeding in Prunus is exclusively accomplished by cross breeding using existing SC strains as a parent. For example, almost all SC sweet cherry ( $P$. avium) cultivars recently released are offspring of JI2420, which is a SC strain produced by X-ray irradiation breeding (Lewis, 1949; Ushijima et al., 2004). SC 'NK14' Japanese apricot (P. mume) is from crosses between self-incompatible 'Nanko' and SC 'Kensaki', a naturally occurring PPM SC cultivar. However, considering the astronomical number of pollen grains present in a single flower and that a mutation in $S F B$ in a single pollen grain could confer selfcompatibility to the pollen grain itself, we should be able to more effectively utilize spontaneous or artificial mutation in SFB for SC breeding, as the SC PPM $S^{4}$ haplotype was artificially produced in sweet cherry (Lewis, 1949).

\section{Acknowledgements}

The authors are grateful to Dr. Ayako Ikegami and Dr. Tomoya Esumi for their assistance in collecting plant materials.

\section{Literature Cited}

de Nettancourt, D. 2001. Incompatibility and incougruity in wild and cultivated plants. Springer-Verlag, Berlin.

Hanada, T., K. Fukuta, H. Yamane, T. Esumi, R. Tao, T. M. Gradziel, A. M. Dandekar, Á. F. Martí, J. M. Alonso and R. Socias i Company. 2009. Cloning and characterization of a 
self-compatible $S^{f}$ haplotype in almond [Prunus dulcis (Mill.) D. A. Webb. syn. P. amygdalus Batsch] to resolve previous confusion in its $S^{f}$-RNase sequence. HortScience 44: 609-613.

Ikeda, K., B. Igic, K. Ushijima, H. Yamane, N. R. Hauck, R. Nakano, H. Sassa, A. F. Iezzoni, J. R. Kohn and R. Tao. 2004. Primary structural features of the $S$ haplotype-specific F-box protein, SFB, in Prunus. Sex. Plant Reprod. 16: 235-243.

Lewis, D. 1949. Structure of the incompatibility gene; induced mutation rate. Heredity 3: 339-355.

Sonneveld, T., K. R. Tobbut, S. P. Vaughan and T. P. Robbins. 2005. Loss of pollen- $S$ function in two self-compatible selections of Prunus avium is associated with deletion/mutation of an $S$ haplotype-specific F-box gene. Plant Cell 17: 37-51.

Tao, R. and A. F. Iezzoni. 2010. The S-RNase-based gametophytic self-incompatibility system in Prunus exhibits distinct genetic and molecular features. Sci. Hortic. 124: 423-433.

Tao, R., H. Yamane, A. Sugiura, H. Murayama, H. Sassa and H. Mori. 1999. Molecular typing of S-alleles through identification, characterization and cDNA cloning for $S$-RNases in sweet cherry. J. Amer. Soc. Hort. Sci. 124: 224-233.

Tao, R., A. Watari, T. Hanada, T. Habu, H. Yaegaki, M. Yamaguchi and H. Yamane. 2007. Self-compatible peach (Prunus persica) has mutant versions of the $S$ haplotypes found in self-incompatible Prunus species. Plant. Mol. Biol. 63: 109123 .

Tsukamoto, T., D. Potter, R. Tao, C. P. Vieira, J. Vieira and A. F. Iezzoni. 2008. Genetic and molecular characterization of three novel $S$-haplotypes in sour cherry (Prunus cerasus L.). J. Exp. Bot. 59: 3169-3185.

Tsukamoto, T., N. R. Hauck, R. Tao, N. Jiang and A. F. Iezzoni. 2010. Molecular and genetic analyses of four nonfunctional $S$ haplotype variants derived from a common ancestral $S$ hap- lotype identified in sour cherry (Prunus cerasus L.). Genetics 184: 411-427.

Ushijima, K., H. Sassa, A. M. Dandekar, T. M. Gradziel, R. Tao and H. Hirano. 2003. Structural and transcriptional analysis of the self-incompatibility locus of almond: Identification of a pollen-expressed F-box gene with haplotype-specific polymorphism. Plant Cell 15: 771-781.

Ushijima, K., H. Yamane, A. Watari, E. Kakehi, K. Ikeda, N. R. Hauck, A. F. Iezzoni and R. Tao. 2004. The $S$ haplotypespecific F-box protein gene, $S F B$, is defective in selfcompatible haplotypes of Prunus avium and P. mume. Plant J. 39: 573-586.

Watari, A., T. Hanada, H. Yamane, T. Esumi, R. Tao, H, Yaegaki, M. Yamaguchi, K. Beppu and I. Kataoka. 2007. A low transcriptional level of $S^{e}$-RNase in the $S^{e}$-haplotype confers self-compatibility in Japanese plum. J. Amer. Soc. Hort. Sci. 132: 396-406.

Yamane, H., K. Ikeda, K. Ushijima, H. Sassa and R. Tao. 2003. A pollen-expressed gene for a novel protein with an F-box motif that is very tightly linked to a gene for S-RNase in two species of cherry, Prunus cerasus and P. avium. Plant Cell Physiol. 44: 764-769.

Yamane, H., R. Tao, A. Sugiura, N. R. Hauck and A. F. Iezzoni. 2001. Identification and characterization of $S$-RNases on tetraploid sour cherry (Prunus cerasus). J. Amer. Soc. Hort. Sci. 126: 661-667.

Yamane, H. and R. Tao. 2009. Molecular basis of self-(in)compatibility and current status of $S$-genotyping in Rosaceous fruits tree. J. Japan. Soc. Hort. Sci. 78: 137-157.

Yamamoto, T., K. Mochida and T. Hayashi. 2003. Shanhai Suimitsuto, one of the origins of Japanese peach cultivars. J. Japan. Soc. Hort. Sci. 72: 116-121. 